\title{
Enhancement of quercetin water solubility with steviol glucosides and the studies of biological properties
}

\author{
Thi Thanh Hanh Nguyen", Shin-Hye Yu², Jiyoun Kim², Eunbae An², Kyeonghwan \\ Hwang $^{3}$, Jun-Seong Park ${ }^{3 *}$, and Doman Kim ${ }^{1,2^{*}}$
}

${ }^{1}$ Research Institute of Food Industrialization, Institutes of Green Bio Science \& Technology, Seoul National University, Pyeongchang-gun, Gangwon-do, 232-916, Korea; ${ }^{2}$ Graduate School of International Agricultural Technology, Seoul National University, Pyeongchang-gun, Gangwon-do, 232-916, Korea; ${ }^{3}$ Skin Research Institute, Amorepacific Corporation R\&D Center, Yongin 314-1, South Korea

\section{*Corresponding authors:}

1. Doman Kim, PhD, Research Institute of Food Industrialization, Institutes of Green Bio Science \& Technology and Graduate School of International Agricultural Technology, Seoul National University, Pyeongchang-gun, Gangwon-do, 232-916, Korea;

2. Jun-Seong Park, PhD, Skin Research Institute, Amorepacific Corporation R\&D Center, Yongin 314-1, South Korea

Submission Date: October 3, 2015, Acceptance date: December 27, 2015: Publication date: December 29, 2015

\begin{abstract}
:
Background: Quercetin, a flavonol contained in various vegetables and fruits, has numerous biological activities which include anticancer, antiviral, anti-diabetic, and anti-oxidative properties. However, quercetin also has low oral bioavailability, due to its insolubility in water. Thus, the bioavailability of quercetin administered to human beings in a capsule form was reported to be less than $1 \%$, with only a small percentage of ingested quercetin getting absorbed in the blood. This leads to certain difficulties in creating highly effective medicines.

Methods: Quercetin-rubusoside and quercetin-rebaudioside were prepared. The antioxidant activities of quercetin and Q-rubusoside were evaluated by DPPH radical scavenging method. Inhibition activities of quercetin and Quercetin-rubusoside were determined by measuring the remaining activity of $3 \mathrm{CL}^{\text {pro }}$ with $200 \mu \mathrm{M}$ inhibitor. The inhibition activity of quercetin, rubusoside and quercetin-rubusoside were determined by measuring the activity of human maltase, which remains at $100 \mu \mathrm{M}$ rubusoside or quercetin-rubusoside. The mushroom tyrosinase inhibition was assayed with the reaction mixture containing $3.3 \mathrm{mM}$ L-DOPA in $50 \mathrm{mM}$ potassium phosphate buffer ( $\mathrm{pH}$ 6.8), and $10 \mathrm{U}$ mushroom tyrosinase/ml with or without quercetin or quercetin-rubusoside.
\end{abstract}


Results: With $10 \%$ rubusoside treatment, quercetin showed solubility of $7.7 \mathrm{mg} / \mathrm{ml}$ in water, and its solubility increased as the concentration of rubusoside increased; the quercetin solubility in water increased to $0.83 \mathrm{mg} / \mathrm{ml}$ as rubusoside concentration increased to $1 \mathrm{mg} / \mathrm{ml}$. Quercetin solubilized in rubusoside solution showed DPPH radical-scavenging activity and mushroom tyrosinase inhibition activity, similar to that of quercetin solubilized in dimethyl-sulfoxide. Quercetin-rubusoside also demonstrated 1.2 and 1.9 folds higher inhibition activity against $3 \mathrm{CL}^{\mathrm{pro}}$ of SARS and human intestinal maltase, respectively, than those of quercetin in DMSO.

Conclusions: Quercetin can be solubilized in water with rebaudioside or rubusoside treatment. $\mathrm{As} \mathrm{Ru}$ concentration increases, the solubility of quercetin in water increases. The solubilization of quercetin in Ru solution did not reduce its biological functions such as the DPPH radicalscavenging and mushroom tyrosinase activity. Additionally, quercetin-rubusoside increased the inhibition activity against the $3 \mathrm{CL}^{\text {pro }}$ of SARS and human intestinal maltase, when compared with the activity of quercetin in DMSO. Therefore, rubusoside and rebaudioside are promising compounds which enhance the solubility of poorly water soluble compounds.

Keywords: rubusoside, rebaudioside, flavonol, quercetin, human maltase, $3 \mathrm{CL}^{\text {pro }}$

\section{INTRODUCTION:}

Flavonoids are polyphenolic secondary metabolites in plants, with a common diphenylpropane (C6-C3-C6) skeleton categorized into chalcones, flavonols, flavones, flavan-3-ols, flavanones, isoflavones, and anthocyanins [1]. Quercetin (3,3',4',5,7-pentahydroxylflavone, Figure 1) is the major representative of the flavonoids subclass of flavonols that are found in abundance in various fruits and vegetables. For example, tea, apples, onions and berries [2]. The average intake of flavonols in the Netherlands [3], United states [4], and Japan [5] is estimated to be around $20 \mathrm{mg} / \mathrm{day}$, of which more than $50 \%$ consists of quercetin. Quercetin has demonstrated an excellent free-radical scavenging antioxidant activity [6], antidiabetic activity [7], inhibitory activity toward SARS-CoV (severe acute respiratory syndrome-associated coronavirus) 3CL ${ }^{\text {pro }}$ [8] or viral replication [9], and it has been proposed to be a chemopreventive and anticancer agent [10-12]. However, due to its chemical structure, the solubility of quercetin is poor. As a result, the bioavailability of quercetin administered to human beings in a capsule form was reported to be less than $1 \%$ [13], with only a small percentage of ingested quercetin getting absorbed in the blood [14]. This leads to certain difficulties in creating highly effective medicines, since solubility is one of the major biopharmaceutical characteristics that largely determines the drug's bioequivalence, in addition to the possibility of creating drug forms which have effective dosage, absorption rate, and completeness [15]. Therefore, various attempts have been made to improve the water solubility of quercetin, such as making quercetin loaded nanostructured lipid carriers [16], encapsulation on poly-D,L-lactide nanoparticles [17], or capsulation using $\beta$-cyclodextrin [18].

Steviol glycosides are natural sweeteners, approximately 200, 300, and 114 times sweeter than sucrose, present in rebaudioside (Reb) A, stevioside (Ste) and rubusoside (Ru, Figure 1), respectively [19-21]. Reb and Ste are diterpenoid glycosides found in high concentration levels 
in the leaves from the Stevia rebaudiana (bertoni) plant commercially cultivated in Japan, Singapore, Taiwan, South Korea, China, Israel, India, Brazil, Australia, and Paraguay [22]; Ru is the main component of the leaves of Rubus suavissimus S. Lee (Rosaceae) which is widely grown in southwestern China and used for Chinese sweet tea. In addition to its use as a sweetener, Chinese sweet leaf has also been used to treat various diseases such as hypertension, diabetes, atherosclerosis, maintaining healthy kidneys, and relieving coughs [23]. Recently, it has been discovered that $\mathrm{Ru}$ showed enhanced solubility of curcumin [24], etoposide A [25], liquiritin and teniposide [26], and paclitaxel [27].

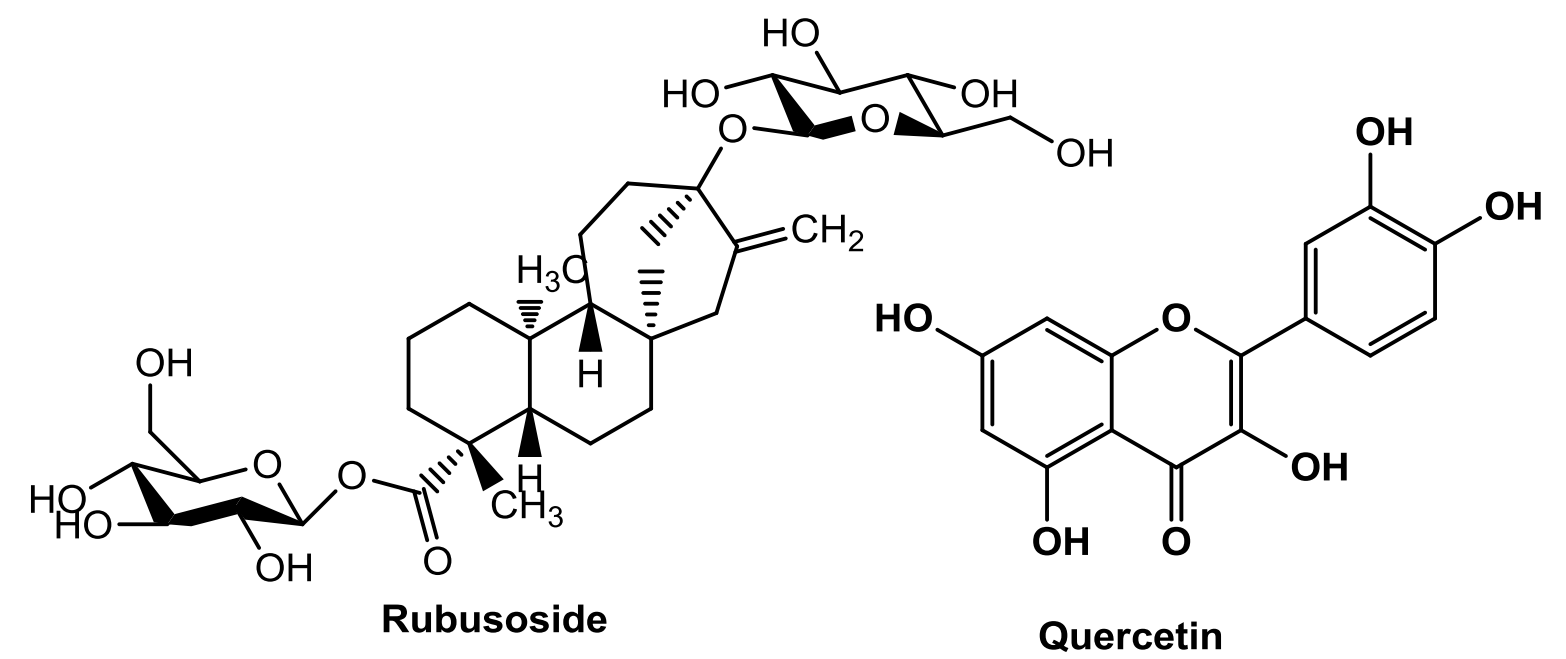

Figure 1. Chemical structures of quercetin and rubusoside

In this study, we found that quercetin solubility was improved in Ru and Reb. The biological properties of quercetin in $\mathrm{Ru}(\mathrm{Q}-\mathrm{Ru})$, such as antioxidant activity, inhibition activities against $3 \mathrm{CL}^{\text {pro }}$ of $\mathrm{SARS}$, human intestinal maltase and tyrosinase were studied. We discovered that they were comparable with those of quercetin solubilized in dimethyl-sulfoxide (DMSO).

\section{MATERIALS AND METHODS:}

\section{Preparation of quercetin in steviol glucoside}

Quercetin and Reb were purchased from Sigma, and Ru was prepared as reported earlier [26]. Q$\mathrm{Ru}$ and quercetin-rebaudioside (Q-Reb) were prepared as reported previously [26], with slight modification. Solubility experiment was carried out as follows: $100 \mathrm{mg}$ of $\mathrm{Ru}$ or Reb, were mixed with $10 \mathrm{mg}$ of quercetin. In a tightly sealed tube, $1 \mathrm{ml}$ of absolute ethanol was added to each mixture, and then vortexed for $15 \mathrm{~min}$ to form a clear ethanol solution. The mixture solution was transferred to an eppendorf tube, and centrifuged at 12,000 rpm for $10 \mathrm{~min}$; the resultant supernatant was transferred to fresh tube. The ethanol was evaporated and the resulting powder was dissolved in $1 \mathrm{ml}$ water. It was then centrifuged at 12,000 rpm for $10 \mathrm{~min}$ and filtered through a $0.20 \mu \mathrm{m}$ membrane (Agilent, Santa Clara, CA, USA). Each compound in the filtrate was analyzed using thin layer chromatography with one ascent of acetonitrile/water 85:15 (v/v). Quercetin on TLC plate was visualized with UV $254 \mathrm{~nm}$, and by dipping the TLC plate into a solvent mixture of $0.5(\mathrm{w} / \mathrm{v}) \mathrm{N}-(1$-naphthy)ethylenediamine dihydrochloride and $5 \%(\mathrm{w} / \mathrm{v})$ 
sulfuric acid in methanol, followed by heating at $120^{\circ} \mathrm{C}$ for $10 \mathrm{~min}$ or $1 \%$ ferric chloride in methanol [6].

The solubility test of quercetin with $\mathrm{Ru}$ or Reb was carried out as follows: $10 \mathrm{mg}$ of quercetin was mixed with $0.5 \%(\mathrm{w} / \mathrm{v}), 1 \%, 2 \%, 3 \%, 4 \%, 5 \%, 7.5 \%$, and $10 \%$ of each Ru or Reb. For the detection of quercetin in the mixture, $1 \%$ ferric chloride in methanol was used. The amount of quercetin solubilized in the $\mathrm{Ru}$ and Reb solution was calculated using the AlphaEaseFC 4.0 program (Alpha Inotech, San Leandro, CA, USA). The standard solution of each $\mathrm{Ru}$ and Reb in DMSO was prepared using concentrations ranging from $1 \mathrm{mg} / \mathrm{ml}$ to 60 $\mathrm{mg} / \mathrm{ml}$.

\section{Antioxidant effect of quercetin solution}

The antioxidant activities of quercetin and $\mathrm{Q}-\mathrm{Ru}$ were evaluated by 2,2-diphenyl-1-picrylhydrazyl-hydrate (DPPH) radical scavenging method as described previously [28]. Quercetin was dissolved in DMSO, or rather the $\mathrm{Q}-\mathrm{Ru}$ and $\mathrm{Ru}$ were dissolved in water. Each solution was mixed with a $100 \mu \mathrm{M}$ DPPH solution to give final concentrations ranging from 0.5 to $200 \mu \mathrm{M}$. After $30 \mathrm{~min}$ at room temperature in total darkness, the absorbance of each mixture was measured at $517 \mathrm{~nm}$ on a microplate reader (Molecular Devices, Sunnyvale, CA, USA). DPPH radical-scavenging activity (SC) was converted into percentage of antioxidant activity, as follows:

$\% \mathrm{SC}=($ Absorbance of control - Absorbance of test sample $) \times 100 /$ Absorbance of control

A linear regression curve was established in order to determine the $\mathrm{SC}_{50}$ values, which is the amount of sample necessary to decrease the absorbance of DPPH by $50 \%$. All the analyses were carried out in triplicate. A value of $p<0.05$ was considered statistically significant.

\section{Inhibition activity of quercetin solution against $3 C L^{\text {pro }}$ of $\mathrm{SARS}$}

The method for the preparation and assay of SARS-3CL ${ }^{\text {pro }}$ activity was used in the same way as previous methods [8]. Inhibition activities of quercetin and Q-Ru were determined by measuring the remaining activity of $3 \mathrm{CL}^{\text {pro }}$ with $200 \mu \mathrm{M}$ inhibitor, as previously reported [29]. Ru or Q-Ru was dissolved in water, and quercetin was dissolved in DMSO as a $10 \mathrm{mM}$ stock solution. The enzyme reaction digest $(100 \mu \mathrm{l})$ was composed of $3 \mu \mathrm{g}$ enzyme, $16 \mu \mathrm{M}$ FRET substrate, and test compound ( 25 to $200 \mu \mathrm{M}$ ) in $20 \mathrm{mM}$ Tris buffer ( $\mathrm{pH} 7.5$ ). Reactions were run for $20 \mathrm{~min}$ at $25^{\circ} \mathrm{C}$, with continuous monitoring of fluorescence with a SpectraMax Gemini XPS (Molecular Devices, Sunnyvale, CA, USA) at excitation and fluorescence emission wavelengths of $355 \mathrm{~nm}$ and 538 $\mathrm{nm}$, respectively. The inhibition was calculated using the following formula (a):

$$
\begin{gathered}
\% \text { inhibition }=100-\text { remaining activity }(\%), \text { where } \\
\text { remaining activity }(\%)=\left[\left(S-S_{o}\right) /\left(C-C_{o}\right)\right] \times 100
\end{gathered}
$$

$C$ is the fluorescence of the control (enzyme, buffer, and substrate). After 18 min incubation, $C_{o}$ is the fluorescence of the control at time zero. After 20 min incubation, $S$ is the fluorescence of the test sample (enzyme, test sample solution, buffer and substrate). And $S_{o}$ is the fluorescence of the test sample at time zero. 
The $50 \%$ inhibitory concentration $\left(\mathrm{IC}_{50}\right)$ was defined as the concentration of $3 \mathrm{CL}^{\text {pro }}$ inhibitor necessary to reduce $3 \mathrm{CL}^{\text {pro }}$ activity by $50 \%$, relative to a reaction mixture containing $3 \mathrm{CL}^{\text {pro }}$ enzyme without inhibitor.

\section{Inhibition activity of quercetin solution against human intestinal maltase}

The preparation and activity assay of human intestinal maltase (HMA) were conducted as reported previously [30]. The inhibition activity of quercetin, $\mathrm{Ru}$ and $\mathrm{Q}-\mathrm{Ru}$ were determined by measuring the activity of HMA which remains at $100 \mu \mathrm{M} \mathrm{Ru}$ or $\mathrm{Q}-\mathrm{Ru}$. $\mathrm{Ru}$ and $\mathrm{Q}-\mathrm{Ru}$ were dissolved in water, and quercetin was dissolved in DMSO, as $10 \mathrm{mM}$ stock solutions. The reaction mixture composed of $0.04 \mathrm{U}$ of enzyme, $5 \mathrm{mM}$ maltose, test compound at different concentrations ranging from $0.001 \mathrm{mM}$ to $1 \mathrm{mM}$ in $50 \mathrm{mM}$ potassium phosphate buffer ( $\mathrm{pH} 6.5$ ), maintained at $37^{\circ} \mathrm{C}$ for $30 \mathrm{~min}$. The control reaction was carried out by following the same inhibition assay protocol, except that buffer was used instead of the test compound. The reaction was stopped by adding $0.2 \mathrm{ml}$ of $2 \mathrm{M}$ Tris- $\mathrm{Cl}(\mathrm{pH}$ 8.0). Enzymatic activity was measured by the glucose oxidase-peroxidase (GOP) method using a Glucose-E kit (BMI, Sungnam, Korea). The $50 \%$ inhibition concentration $\left(\mathrm{IC}_{50}\right)$ was defined as the concentration of HMA inhibitor necessary to reduce HMA activity by $50 \%$, relative to a reaction mixture containing HMA enzyme without inhibitor.

\section{Inhibition activity of quercetin solution against mushroom tyrosinase}

The mushroom tyrosinase (EC 1.14.18.1) used for the bioassay was purchased from Sigma.

The reaction mixture contained $3.3 \mathrm{mM}$ L-DOPA (L-3,4-dihydroxypheylalanine) in $50 \mathrm{mM}$ potassium phosphate buffer ( $\mathrm{pH}$ 6.8), and $10 \mathrm{U}$ mushroom tyrosinase/ml with or without Q or Q$\mathrm{Ru}(0.001$ to $1 \mathrm{mM})$. The reaction was run for $15 \mathrm{~min}$ using 96-well plate, and monitored using a microplate reader (Molecular Devices, Sunnyvale, CA, USA) at $475 \mathrm{~nm}$. The inhibition was calculated using following formula (b):

$$
\begin{aligned}
& \% \text { inhibition }=100-\text { remaining activity }(\%), \text { where } \\
& \text { remaining activity }(\%)=\left[\left(S-S_{o}\right) /\left(C-C_{o}\right)\right] \times 100
\end{aligned}
$$

$C$ is the absorbance of the control (enzyme, buffer, and substrate) after 15 min incubation, $C_{o}$ is the absorbance of the control at time zero, $S$ is the absorbance of the test sample (enzyme, inhibitor, buffer and substrate) after $15 \mathrm{~min}$ incubation, and $S_{o}$ is the absorbance of the inhibitor at time zero.

The 50\% inhibition concentration $\left(\mathrm{IC}_{50}\right)$ was defined as the concentration of inhibitor necessary to reduce the mushroom tyrosinase activity by $50 \%$, relative to a reaction mixture containing mushroom tyrosinase without inhibitor.

\section{RESULTS AND DISCUSSION:}

\section{Solubility of quercetin in rubusoside or rebaudioside}

Quercetin (Figure 1) is a phytochemical belonging to the flavonol subgroup, and is the most ubiquitous dietary flavonoid. Apples and onions are primary sources in the Western diet. Other foods containing quercetin include citrus fruits, berries, red grapes, red wine, broccoli, bark roots, flowers and tea [31]. Recently, quercetin has drawn attention for its remarkable scope of health 
benefits, which make quercetin a leading compound for developing new and effective functional foods or medicines [14, 32]. However, orally administered quercetin is poorly absorbed [13, 14]. Many techniques have been used to improve quercetin solubility in water, such as solid lipid nanoparticle, poly-D,L-lactide nanoparticle, $\beta$-cyclodextrin [16-18], and biosynthesis of quercetin-4'-O- $\alpha$-D-glucopyranoside by using dextransucrase [6], or quercetin-3-O-glucoside by using naringinase [33]. Previous studies have reported the solubility of quercetin is a crucial factor for its bioavailability. For example, quercetin dissolved in DMSO/polyethylene glycol 200 has up to 1.3 fold bioavailability in rats compared with that suspended in $0.7 \% \mathrm{CMC}$ solution [34]. Bioavailability of quercetin was increased 5.7 fold by administration using a solid lipid nanoparticle as an oral delivery carrier, compared with those administered as a quercetin suspension [16]. In this study, quercetin was shown to be soluble in Reb and Ru solutions (Figure 2). The solubility of quercetin was detected under UV light and with ferric chloride staining detecting the phenol ring (Figure 2, lane 2, 3).
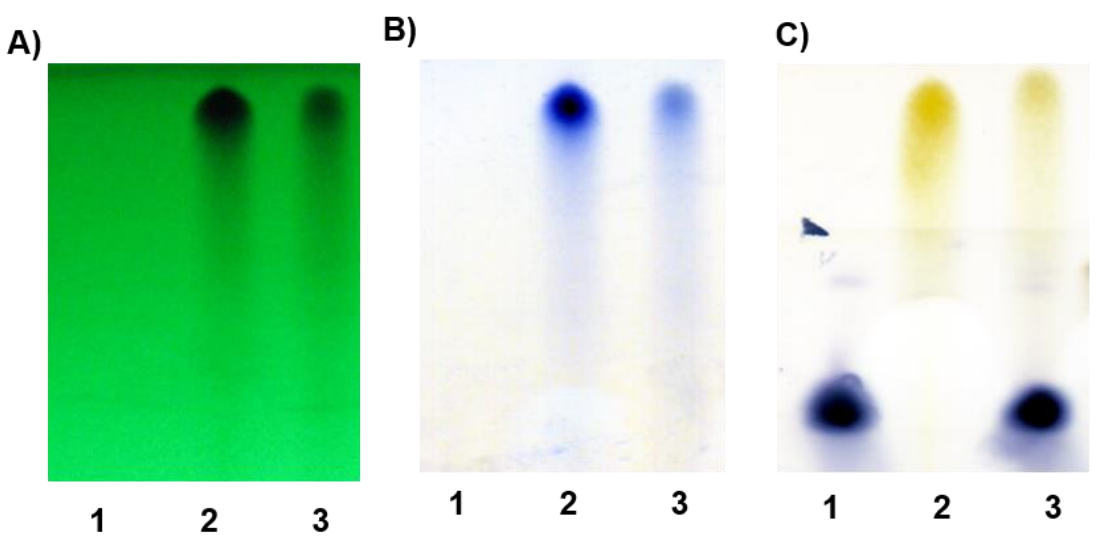

Figure 2. TLC analyses of solubilization of quercetin in water reconstituted from Q-Ru, under UV light at 254nm (A), ferric chloride staining (B), sulfuric acid in methanol (C). Lane 1: Ru; lane 2: $10 \mathrm{mg} / \mathrm{ml}$ of quercetin in DMSO; lane 3: $6 \mathrm{mg} / \mathrm{ml}$ of quercetin in $\mathrm{Ru}$.

The quercetin solubility increased when the Reb or Ru concentrations increased. Quercetin was dissolved up to $0.6 \mathrm{mg} / \mathrm{ml}$ in the presence of $5 \%$ (w/v) Reb (Table 1). As Reb increased to $7.5 \%$ and $10 \%(\mathrm{w} / \mathrm{v})$, the amount of quercetin in water also increased to $0.9 \mathrm{mg} / \mathrm{ml}$ and 1.5 $\mathrm{mg} / \mathrm{ml}$, respectively (Table 1). A linear relationship was found between the concentrations of quercetin and Reb, which was $\mathrm{Y}=0.18 \times \mathrm{A}-0.37$ [where $\mathrm{Y}$ (quercetin concentration, mg/ml) and $\mathrm{A}$ (Reb concentration, $\left.\mathrm{mg} / \mathrm{ml}) ; \mathrm{R}^{2}=0.95\right]$. Thus, every $\mathrm{mg} / \mathrm{ml}$ Reb would result in 0.18 $\mathrm{mg} / \mathrm{ml}$ additional solubility increase of quercetin in water. In the presence of $2 \%(\mathrm{w} / \mathrm{v}) \mathrm{of} \mathrm{Ru}$, quercetin was solubilized to $1.1 \mathrm{mg} / \mathrm{ml}$ (Table 1). As Ru increased to $2 \%, 3 \%, 4 \%, 5 \%, 7.5 \%$ and $10 \%(\mathrm{w} / \mathrm{v})$, soluble quercetin in water also increased to $1.1,1.9,2.6,3.8,7.0$ and $7.7 \mathrm{mg} / \mathrm{ml}$, respectively (Table 1). A linear relationship was found between the concentrations of quercetin and $\mathrm{Ru}$, which was $\mathrm{Y}=0.83 \times \mathrm{B}-0.58$ [where $\mathrm{Y}$ (quercetin concentration in $\mathrm{mg} / \mathrm{ml}$ ) and $\mathrm{B}(\mathrm{Ru}$ concentration in $\mathrm{mg} / \mathrm{ml}) ; \mathrm{R}^{2}=0.98$ ]. As a result, every $\mathrm{mg} / \mathrm{ml} \mathrm{Ru}$ would result in $0.83 \mathrm{mg} / \mathrm{ml}$ additional solubility increase of quercetin in water. Because quercetin showed stronger solubility 
in $\mathrm{Ru}$ than Reb, Q-Ru was selected for further studies of the biological properties of quercetin, and compared with those of quercetin in DMSO.

Table 1. The solubility of quercetin at different concentrations of rebaudioside and rubusoside

\begin{tabular}{|c|c|c|}
\hline \multirow{2}{*}{$\begin{array}{c}\text { Rebaudoside or } \\
\text { Rubusoside added }(\%)\end{array}$} & Rebaudioside & Rubusoside \\
\hline & \multicolumn{2}{|c|}{ Quercetin solubilized in solution $(\mathrm{mg} / \mathrm{ml})$} \\
\hline 0.5 & ND & ND \\
\hline 1.0 & ND & ND \\
\hline 2.0 & ND & $1.1 \pm 0.4$ \\
\hline 30 & ND & $1.9 \pm 0.3$ \\
\hline 3.0 & ND & $2.6 \pm 0.3$ \\
\hline 4.0 & $0.6 \pm 0.1$ & $3.8 \pm 0.5$ \\
\hline 5.0 & $0.9 \pm 0.1$ & $7.0 \pm 0.9$ \\
\hline 7.5 & $1.5 \pm 0.1$ & $7.7 \pm 0.5$ \\
\hline 10 & & \\
\hline
\end{tabular}

$10 \mathrm{mg} / \mathrm{ml}$ quercetin was used. ND: Not detected in solution

\section{Antioxidant activity of quercetin in solution}

For DPPH radical scavenging activity, quercetin or $\mathrm{Q}-\mathrm{Ru}$ were prepared and tested at concentrations ranging from 0.5 to $200 \mu \mathrm{M}$. The $\mathrm{SC}_{50}$ of quercetin solubilized in DMSO (37.4 $\mu \mathrm{M})$ was similar with that of quercetin in Ru solution $(37.3 \mu \mathrm{M})$ (Table 2, Figure 3). This result indicates that the solubilization of quercetin in $\mathrm{Ru}$ does not reduce its antioxidant activity. Therefore, when considering both antioxidant activity and solubility, Q-Ru would be better than quercetin-4'-O- $\alpha$-D-glucopyranoside synthesis, since it has solubility in water of $3.9 \mathrm{mg} / \mathrm{ml}$ but its $\mathrm{SC}_{50}$ was 3.9 times higher than $\mathrm{SC}_{50}$ of quercetin in $\mathrm{DMSO}$ [6].

Table 2. Biological properties of quercetin solubilized in DMSO and in rubusoside

\begin{tabular}{lccc}
\hline \multicolumn{1}{c}{ Biological properties } & $\begin{array}{c}\text { Rubusoside } \\
\text { in water }\end{array}$ & \multicolumn{2}{c}{ Quercetin solubilized in } \\
\cline { 3 - 4 } & & DMSO & Rubusoside solution \\
\hline $\begin{array}{l}\text { DPPH radical-scavenging activity }\left[\mathrm{SC}_{50}\right. \\
(\mu \mathrm{M})]\end{array}$ & - & $37.4 \pm 1.4$ & $37.3 \pm 1.3$ \\
$3 \mathrm{CL}^{\text {pro }}$ of SARS inhibition activity $\left[\mathrm{IC}_{50}\right.$ & $12.6 \times 10^{3}$ & $89.7 \pm 1.4$ & $75.4 \pm 1.1$ \\
$(\mu \mathrm{M})]$ & & & \\
$\mathrm{HMA}$ inhibition activity $\left[\mathrm{IC}_{50}(\mu \mathrm{M})\right]$ & $530 \pm 16$ & $74.0 \pm 1.5$ & $38.5 \pm 0.5$ \\
$\begin{array}{l}\text { Mushroom tyrosinase inhibition activity } \\
{\left[\mathrm{IC}_{50}(\mu \mathrm{M})\right]}\end{array}$ & - & $78.9 \pm 1.7$ & $78.6 \pm 3.0$ \\
\hline
\end{tabular}




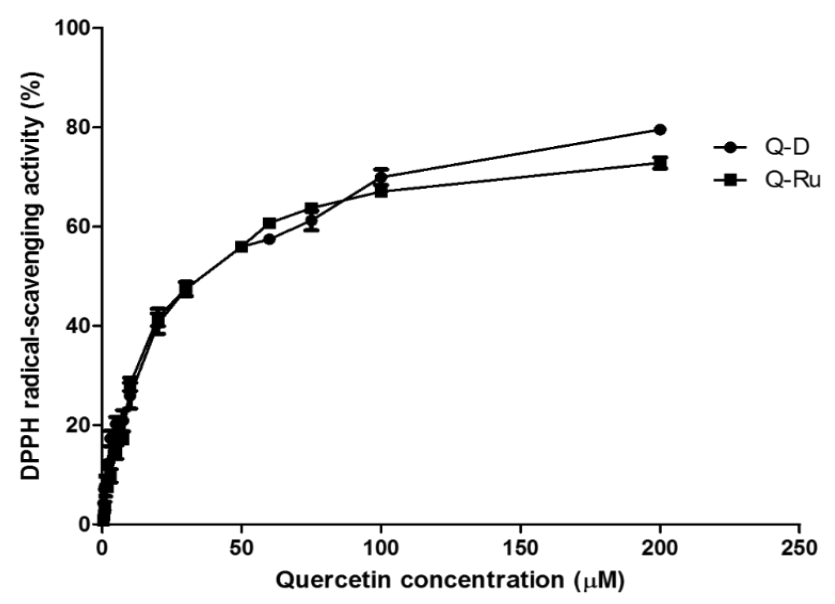

Figure 3. DPPH radical scavenging activities of quercetin solubilized in DMSO and of quercetin solubilized in rubusoside solution. Quercetin in DMSO $(\bullet)$, Quercetin in rubusoside (๘). Each sample $(0.50 \sim$ $200 \mu \mathrm{M}$ ) was mixed with a $100 \mu \mathrm{M} \mathrm{DPPH}$, and kept in dark at room temperature for $30 \mathrm{~min}$. The absorbance was monitored at $517 \mathrm{~nm}$. Each value is mean $\pm \operatorname{SEM}(\mathrm{n}=3)$.

\section{Inhibitory effect of quercetin against $3 \mathrm{CL}^{\text {pro }}$ activity of SARS coronavirus}

The $3 \mathrm{C}$-like protease $\left(3 \mathrm{CL}^{\mathrm{pro}}\right.$ ) of SARS-CoV is one of the most promising targets for discovery of drugs against SARS, because of its critical role in the life cycle of the virus [29, 35]. Quercetin is known to be active against herpes simplex, adeno-, respiratory syncytial, Rous sarcoma, pseudorabies, and parainfluenza viruses [36, 37], and the SARS coronavirus [8, 38], due to its mechanism which inhibits replication. The inhibitory activity of Q-Ru was compared with DMSO-solubilized quercetin using Dabcyl-KTSAVLQSGFRKME-Edans fluorogenic peptide as a substrate. Ru showed $\mathrm{IC}_{50}$ of $12.6 \times 10^{3} \mu \mathrm{M}$ against $3 \mathrm{CL}^{\text {pro }}$ (Table 2, Figure 4). The $\mathrm{IC}_{50}$ of quercetin in DMSO and Ru solution was $89.7 \mu \mathrm{M}$ and $75.4 \mu \mathrm{M}$, respectively (Table 2). Therefore, the combined inhibitory effect of quercetin with $\mathrm{Ru}$ in water increased 1.2 fold against the $3 \mathrm{CL}^{\text {pro }}$ activity.

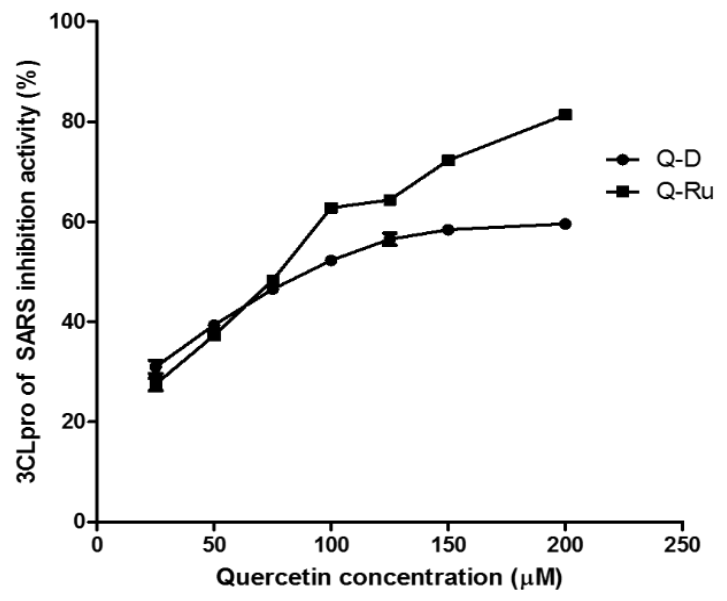

Figure 4. The inhibitory activity of quercetin solubilized in DMSO (Q-D) and quercetin solubilized in rubusoside $(\mathrm{Q}-\mathrm{Ru})$ solution against $3 \mathrm{CL}^{\mathrm{pro}}$ of SARS. The reaction mixture was composed of $3 \mu \mathrm{g}$ enzyme, $16 \mu \mathrm{M}$ FRET substrate, each test compound $(25 \sim 200 \mu \mathrm{M})$ in $20 \mathrm{mM}$ Tris buffer $(\mathrm{pH}$ 7.5). Reactions were run for $20 \mathrm{~min}$ at $25^{\circ} \mathrm{C}$, with continuous monitoring of fluorescence using a SpectraMax Gemini XPS apparatus, at excitation and fluorescence emission wavelengths of $355 \mathrm{~nm}$ and $538 \mathrm{~nm}$, respectively. 


\section{Inhibitory effect of quercetin in Ru solution against human intestinal maltase}

HMA hydrolyzes linear $\alpha$-1,4-linked oligosaccharide substrates, plays a crucial role in the production of glucose in the human lumen, and acts as an efficient drug target for type 2 diabetes and obesity [39, 40]. The HMA inhibitory activity of $\mathrm{Ru}$, quercetin in DMSO, and Q-Ru at different concentrations (0.001 to $1 \mathrm{mM}$ ) were investigated (Figure 5). Q-Ru showed higher HMA inhibition than that of quercetin solubilized in DMSO. Ru also showed inhibition against HMA activity with $\mathrm{IC}_{50}$ of $530 \mu \mathrm{M}$. Quercetin in DMSO and Ru showed inhibition of HMA activity with $\mathrm{IC}_{50}$ of $74.0 \mu \mathrm{M}$ and $38.5 \mu \mathrm{M}$ (Table 2, Figure 5), respectively. As a result, the quercetin in $\mathrm{Ru}$ increased the HMA inhibition by 1.9 folds.

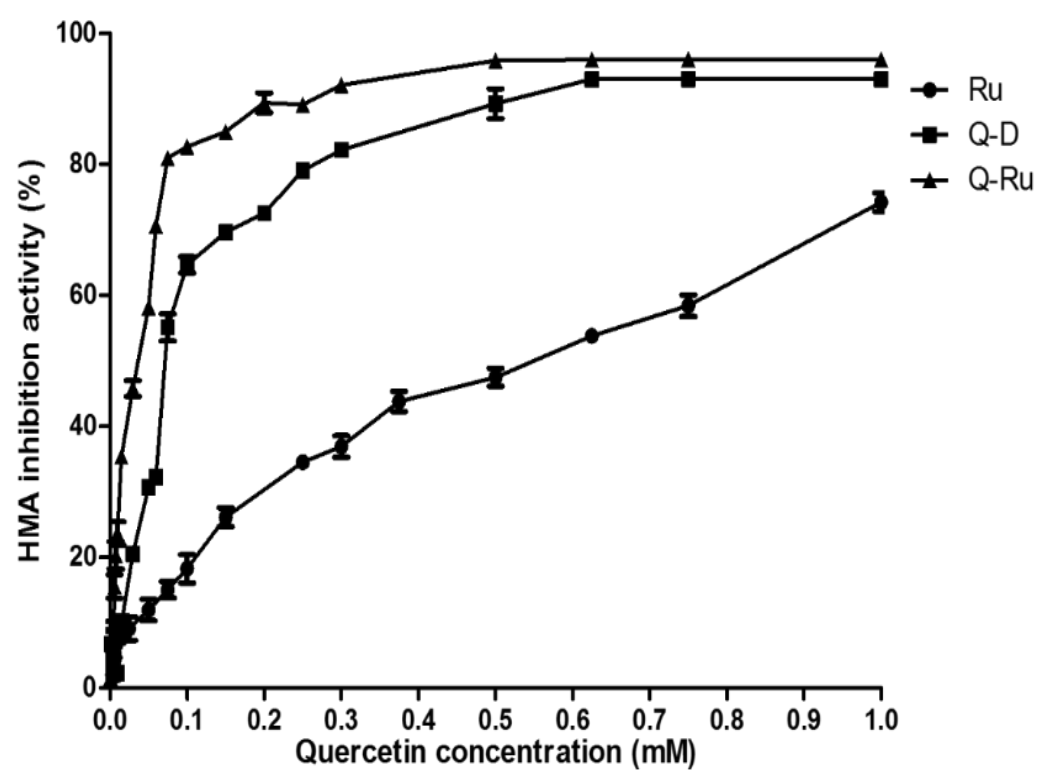

Figure 5. The inhibitory activities of rubusoside $(\mathrm{Ru})$, quercetin solubilized in DMSO (Q-D) and quercetin solubilized in rubusoside $(\mathrm{Q}-\mathrm{Ru})$ solution against HMA. The reaction mixture composed of $0.04 \mathrm{U}$ of enzyme, $5 \mathrm{mM}$ maltose, each test compound $(0.001 \mathrm{mM} \sim 1 \mathrm{mM})$ in 50

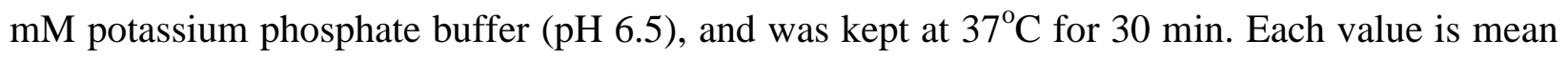
$\pm \operatorname{SEM}(\mathrm{n}=3)$.

\section{Inhibitory effect of quercetin in Ru solution against mushroom tyrosinase}

Tyrosinase (monophenol, dihydroxyl-L-phenylalanine: oxygen oxidoreductase, EC 1.14.18.1) is a copper-containing enzyme, which is widely distributed in microorganisms, animals and plants. It is a key enzyme in melanin biosynthesis, and plays a crucial role in determining the color of mammalian skin and hair [41]. During melanoma, the uncontrolled tyrosinase activity results in increased melanin synthesis [42]. The inhibition of mushroom tyrosinase was evaluated using different concentrations of quercetin in DMSO and Q-Ru (0.001 to $1.0 \mathrm{mM})$. The inhibition of mushroom tyrosinase by quercetin in DMSO and Q-Ru is shown in Figure 6. Q-Ru demonstrated similar tyrosinase inhibition activity as quercetin solubilized in DMSO, with an $\mathrm{IC}_{50}$ of 78.6 and $78.9 \mu \mathrm{M}$, respectively (Table 2, Figure 6). 


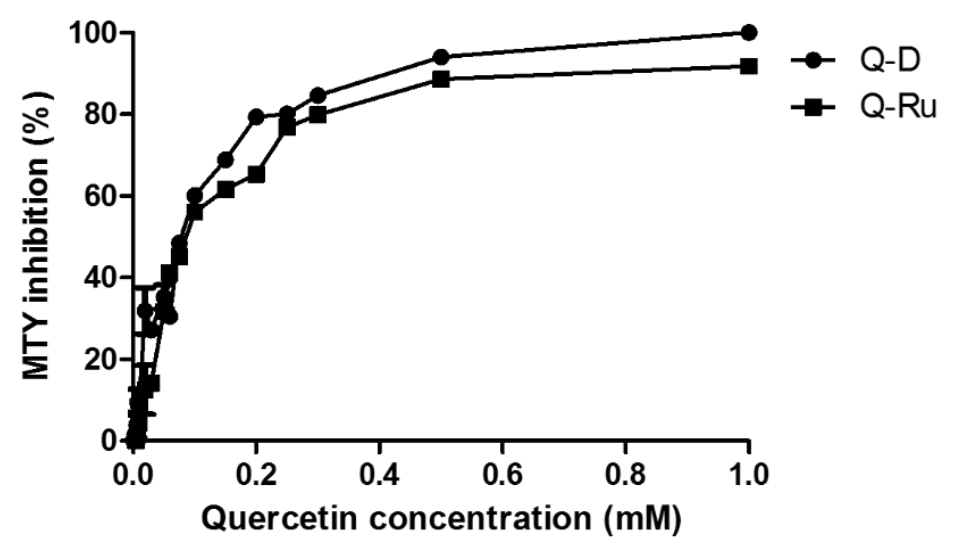

Figure 6. The inhibitory activity of quercetin solubilized in DMSO (Q-D) and of quercetin solubilized in rubusoside $(\mathrm{Q}-\mathrm{Ru})$ solution against mushroom tyrosinase. The reaction mixture contained 3.3 mM L-DOPA (L-3,4-dihydroxypheylalanine), $10 \mathrm{U} / \mathrm{ml}$ mushroom tyrosinase, different concentration of each test compound $(1.0 \sim 1000 \mu \mathrm{M})$ in $50 \mathrm{mM}$ potassium phosphate buffer ( $\mathrm{pH}$ 6.8), with or without quercetin and Q-Ru; reaction was for $15 \mathrm{~min}$, and the absorbance was monitored at $475 \mathrm{~nm}$. Each value is mean $\pm \operatorname{SEM}(\mathrm{n}=3)$.

\section{CONCLUSIONS:}

The present study demonstrated that quercetin can be solubilized in water with rebaudioside or rubusoside treatment. As $\mathrm{Ru}$ concentration increases, the solubility of quercetin in water increases. Interestingly, the solubilization of quercetin in $\mathrm{Ru}$ solution did not reduce its biological functions such as the DPPH radical-scavenging and mushroom tyrosinase activity. Additionally, Q-Ru increased the inhibition activity against the $3 \mathrm{CL}^{\text {pro }}$ of SARS and human intestinal maltase, when compared with the activity of quercetin in DMSO. Therefore, Ru and rebaudioside are promising compounds which enhance the solubility of poorly water soluble compounds (including quercetin, rutin and astragallin). Studies pertaining to the biological functions of the solubilized quercetin in Ru and Reb are currently in progress.

\section{Competing Interests:}

The authors have no financial interests or conflicts of interest.

\section{Authors' Contributions:}

All authors contributed to this study. D.K. and J.P. designed experiments. T.T.H.N., S.Y., J.K., E.A. and K.H. performed experiments. D.K., T.T.H.N. and J.P. wrote the manuscript.

\section{Abbreviation:}

Q-Ru, quercetin solubilized in rubusoside; DMSO, dimethyl-sulfoxide; DPPH, 2,2-diphenyl-1picryl-hydrazyl-hydrate; SARS-CoV, severe acute respiratory syndrome-associated coronavirus; $3 \mathrm{CL}^{\text {pro }}$, 3C like protease; Reb, rebaudioside A; Ste, stevioside, Ru, rubusoside; SC, DPPH radical-scavenging activity; FRET, fluorescence resonance energy transfer; HMA, human intestinal maltase; GOP, glucose oxidase-peroxidase; L-DOPA, L-3,4-dihydroxypheylalanine; ND, not detected in solution. 


\section{Acknowledgement and Fundings:}

This work was partially supported by Research Resettlement Fund for the new faculty of Seoul National University (D. Kim), by Basic Science Research Program through the National Research Foundation of Korea (NRF) funded by the Ministry of Education (2015R1D1A4A01020522; TTH Nguyen) and by AmorePacific Corporation.

\section{REFERENCES:}

1. Kawabata K, Mukai R, Ishisaka A: Quercetin and related polyphenols: new insights and implications for their bioactivity and bioavailability. Food Funct 2015, 6: 1399-1417.

2. Sultana B, Anwar F: Flavonols (kaempeferol, quercetin, myricetin) contents of selected fruits, vegetables and medicinal plants. Food Chem 2008, 108: 879-884.

3. Hertog MGL, Hollman PCH, Katan MB, Kromhout D: Intake of potentially anticarcinogenic flavonoids and their determinants in adults in the Netherlands. Nutr Cancer 1993, 20: 21-29.

4. Sampson L, Rimm E, Hollman PCH, de Vries JHM, Katan MB: Flavonol and flavone intakes in US health professionals. J Am Diet Assoc 2002, 102: 1414-1420.

5. Arai Y, Watanabe S, Kimira M, Shimoi K, Mochizuki R, Kinae N: Dietary intakes of flavonols, flavones and isoflavones by Japanese women and the inverse correlation between quercetin intake and plasma LDL cholesterol concentration. J Nutr 2000, 130: 2243-2250.

6. Moon YH, Lee JH, Jhon DY, Jun WJ, Kang SS, Sim J, Choi H, Moon JH, Kim D: Synthesis and characterization of novel quercetin-alpha-D-glucopyranosides using glucansucrase from Leuconostoc mesenteroides. Enzyme Microb Tech 2007, 40: 11241129.

7. Pandey KB, Rizvi SI: Plant polyphenols as dietary antioxidants in human health and disease. Oxid Med Cell Longev 2009, 2: 270-278.

8. Thi THN, Woo HJ, Kang HK, Nguyen VD, Kim YM, Kim DW, Ahn SA, Xia YM, Kim D: Flavonoid-mediated inhibition of SARS coronavirus 3C-like protease expressed in Pichia pastoris. Biotechnol Lett 2012, 34: 831-838.

9. Lin CW, Tsai FJ, Tsai CH, Lai, CC, Wan L, Ho TY, Hsieh CC, Chao PDL: Anti-SARS coronavirus $3 \mathrm{C}$-like protease effects of Isatis indigotica root and plant-derived phenolic compounds. Antivir Res 2005, 68: 36-42.

10. Martinez-Perez C, Ward C, Cook G, Mullen P, McPhail D, Harrison DJ, Langdon SP: Novel flavonoids as anti-cancer agents: mechanisms of action and promise for their potential application in breast cancer. Biochem Soc Trans 2014, 42: 1017-1023.

11. Gibellini L, Pinti M, Nasi M, Montagna JP, De Biasi S, Roat E, Bertoncelli L, Cooper E L, Cossarizza, A: Quercetin and cancer chemoprevention. Evid-Based Compl Alt 2011, 1-15.

12. Zheng SY, Li Y, Jiang D, Zhao J, Ge JF: Anticancer effect and apoptosis induction by quercetin in the human lung cancer cell line A-549. Mol Med Rep 2012, 5: 822-826.

13. Gugler R, Leschik M, Dengler HJ: Disposition of quercetin in man after single oral and intravenous doses. Eur J Clin Pharmacol 1975, 9: 229-234. 
14. D'Archivio M, Filesi C, Vari R, Scazzocchio B, Masella R: Bioavailability of the polyphenols: status and controversies. Int J Mol Sci 2010, 11: 1321-1342.

15. Lipkovska NA, Barvinchenko VN, Fedyanina TV: Dependence of the solubility of natural flavonoids in water on the concentration of miramistin, polyvinylpyrrolidone, and human serum albumin. Russ J Phys Chem a+ 2014, 88: 881-885.

16. Li H, Zhao X, Ma Y, Zhai G, Li L, Lou H: Enhancement of gastrointestinal absorption of quercetin by solid lipid nanoparticles. J Control Release 2009, 133: 238-244.

17. Kumari A, Yadav SK, Pakade YB, Kumar V, Singh B, Chaudhary A, Yadav SC: Nanoencapsulation and characterization of Albizia chinensis isolated antioxidant quercitrin on PLA nanoparticles. Colloids Surf B Bionterfaces 2011, 82: 224-232.

18. Zheng Y, Haworth IS, Zuo Z, Chow MS, Chow AH: Physicochemical and structural characterization of quercetin-beta-cyclodextrin complexes. J Pharm Sci 2005, 94: 10791089.

19. Prakash, I., DuBois, G. E., Cios, J. F., Wilkens, K. L., Fosdick, L. E., Development of rebiana, a natural, non-caloric sweetener. Food Chem Toxicol 2008, 46, S75-S82.

20. Upreti M, Dubois G, Prakash I: Synthetic study on the relationship between structure and sweet taste properties of steviol glycosides. Molecules 2012, 17: 4186-4196.

21. Ko JA, Kim YM, Ryu YB, Jeong HJ, Park TS, Park SJ, Wee YJ, Kim JS, Kim D, Lee WS: Mass production of rubusoside using a novel stevioside-Specific beta-glucosidase from Aspergillus aculeatus. J Agric Food Chem 2012, 60: 6210-6216.

22. Upreti M, Strassburger K, Chen YL, Wu SX, Prakash I: Solubility enhancement of steviol glycosides and characterization of their inclusion complexes with gammacyclodextrin. Int J Mol Sci 2011, 12: 7529-7553.

23. Koh GY, Chou G, Liu Z: Purification of a water extract of Chinese sweet tea plant (Rubus suavissimus S. Lee) by alcohol precipitation. J Agric Food Chem 2009, 57: 5000-5006.

24. Zhang F, Koh GY, Jeansonne DP, Hollingsworth J, Russo PS, Vicente G, Stout RW, Liu ZJ: A novel solubility-enhanced curcumin formulation showing stability and maintenance of anticancer activity. J Pharm Sci 2011, 100: 2778-2789.

25. Zhang F, Koh GY, Hollingsworth J, Russo PS, Stout RW, Liu Z: Reformulation of etoposide with solubility-enhancing rubusoside. Int J Pharm 2012, 434: 453-459.

26. Nguyen TT, Jung SJ, Kang HK, Kim YM, Moon YH, Kim M, Kim D: Production of rubusoside from stevioside by using a thermostable lactase from Thermus thermophilus and solubility enhancement of liquiritin and teniposide. Enzyme Microb Technol 2014, 64-65: 38-43.

27. Liu ZJ, Zhang F, Koh GY, Dong X, Hollingsworth J, Zhang J, Russo PS, Yang PY, Stout RW: Cytotoxic and antiangiogenic paclitaxel solubilized and permeationenhanced by natural product nanoparticles. Anti-Cancer Drug 2015, 26: 167-179.

28. Kang J, Kim YM, Kim N, Kim DW, Nam SH, Kim D: Synthesis and characterization of hydroquinone fructoside using Leuconostoc mesenteroides levansucrase. Appl Microbiol Biotechnol 2009, 83: 1009-1016. 
29. Hanh Nguyen TT, Ryu HJ, Lee SH, Hwang S, Breton V, Rhee JH, Kim D: Virtual screening identification of novel severe acute respiratory syndrome 3C-like protease inhibitors and in vitro confirmation. Bioorg Med Chem Lett 2011, 21: 3088-3091.

30. Thi THN, Jung SH, Lee S, Ryu HJ, Kang HK, Moon YH, Kim YM, Kimura A, Kim D: Inhibitory effects of epigallocatechin gallate and its glucoside on the human intestinal maltase inhibition. Biotechnol Bioproc E 2012, 17: 966-971.

31. Garcia-Saura MF, Galisteo M, Villar IC, Bermejo A, Zarzuelo A, Vargas F, Duarte J: Effects of chronic quercetin treatment in experimental renovascular hypertension. Mol Cell Biochem 2005, 270: 147-155.

32. Zhang HS, Zhang M, Yu LH, Zhao Y, He NW, Yang XB: Antitumor activities of quercetin and quercetin-5 ',8-disulfonate in human colon and breast cancer cell lines. Food Chem Toxicol 2012, 50: 1589-1599.

33. Lee YS, Huh JY, Nam SH, Kim D, Lee SB: Synthesis of quercetin-3-O-glucoside from rutin by Penicillium decumbens naringinase. J Food Sci 2013, 78: C411-C415.

34. Khaled KA, El-Sayed YM, Al-Hadiya BM: Disposition of the flavonoid quercetin in rats after single intravenous and oral doses. Drug Dev Ind Pharm 200, 29: 397-403.

35. Chen L, Li J, Luo C, Liu H, Xu W, Chen G, Liew OW, Zhu W, Puah CM, Shen X, Jiang $\mathrm{H}$ : Binding interaction of quercetin-3-beta-galactoside and its synthetic derivatives with SARS-CoV 3CL(pro): structure-activity relationship studies reveal salient pharmacophore features. Bioorg Med Chem 2006, 14: 8295-306.

36. Chiang LC, Chiang W, Liu MC, Lin CC: In vitro antiviral activities of Caesalpinia pulcherrima and its related flavonoids. J Antimicrob Chemother 2003, 52: 194-198.

37. Formica JV, Regelson W: Review of the biology of quercetin and related bioflavonoids. Food Chem Toxicol 1995, 33: 1061-1080.

38. Yi L, Li ZQ, Yuan KH, Qu XX, Chen J, Wang GW, Zhang H, Luo HP, Zhu LL, Jiang PF, Chen LR, Shen Y, Luo M, Zuo GY, Hu JH, Duan DL, Nie YC, Shi XL, Wang W, Han Y, Li TS, Liu YQ, Ding MX, Deng HK, Xu XJ: Small molecules blocking the entry of severe acute respiratory syndrome coronavirus into host cells. J Virol 2004, 78: 11334-11339.

39. Ren LM, Qin XH, Cao XF, Wang LL, Bai F, Bai G, Shen YQ: Structural insight into substrate specificity of human intestinal maltase-glucoamylase. Protein Cell 2011, 2: 827-836.

40. Nguyen TT, Ryu HJ, Lee SH, Hwang S, Cha J, Breton V, Kim D: Discovery of novel inhibitors for human intestinal maltase: virtual screening in a WISDOM environment and in vitro evaluation. Biotechnol Lett 2011, 33: 2185-91.

41. delMarmol V, Beermann F: Tyrosinase and related proteins in mammalian pigmentation. Febs Lett 1996, 381: 165-168.

42. Solano F, Briganti S, Picardo M, Ghanem G: Hypopigmenting agents: an updated review on biological, chemical and clinical aspects. Pigm Cell Res 2006, 19: 550-571. 